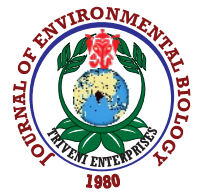

\title{
Identification of Swarna x O. nivara (RPBio4918) advanced backcross lines performing well under acidic soil conditions
}

\author{
A. Debnath ${ }^{1 *}$, M. Rai ${ }^{2}$ and W. Tyagi \\ 'Department of Genetics and Plant Breeding, College of Agriculture, Acharya Narendra Deva University of Agriculture \& Technology, Kumarganj-224 229, India \\ ${ }^{2} S$ chool of Crop Improvement, College of Post Graduate Studies in Agricultural Sciences, Central Agricultural University (Imphal), Umiam-793 103, India \\ *Corresponding Author Email : adebnathagri@gmail.com
}

\section{Abstract}

Aim: To evaluate a set of ABLs (Advanced Backcross Lines) to identify lines perfoming well under acidic soil and iron toxicity hydroponics conditions.

Methodology: A total of 194 ABLs were randomly used in lowland field randomly following augmented experimental design. Selected lines were screened in hydroponics condition using Yoshida's solution for iron toxicity tolerance.

Results: Under field conditions, several deficiencies and toxicities often co-exist, and it becomes difficult to partition the effect of different stresses on the genotypes. Therefore, screening genotypes in artificial hydroponics conditions allows us to dissect the response of a genotype to one particular nutrient toxicity or deficiency. Based on different traits superior, average and inferior performing lines were selected from field condition. Hydroponic experiment was conducted using Yoshida's solution for iron toxicity screening, different superior and inferior lines were identified based on the parameters like root growth, root and shoot biomass. Four lines K 408, K 455, S 304, S 203 were identified that performed well in both field and Fe toxic hydroponic conditions.

Interpretation: The information generated would help to identify suitable parents for breeding program under acidic soils, and the phenotypic data on ABLs may serve as a base for future mapping of loci responsible for yield under acidic soils and iron toxic conditions.

Key words: Acidic soil, Advanced backcross lines, Hydroponic condition, Iron toxicity, Seedling stage screening

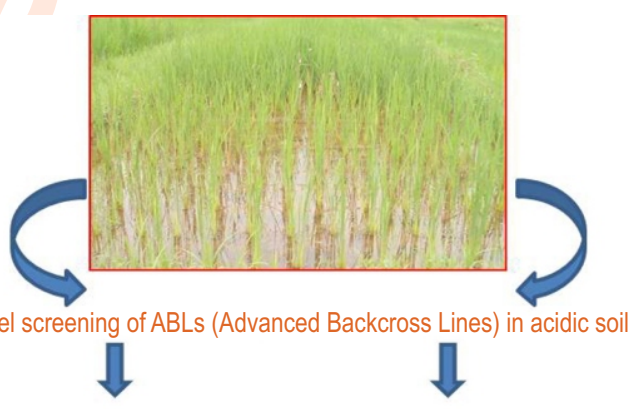

Superior and inferior performing lines were selected based on different traits

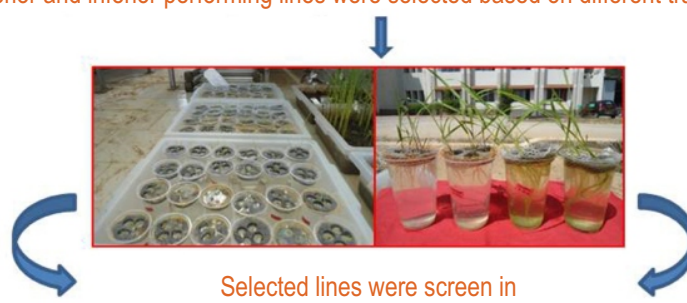

hydroponic condition using Yoshida's solution for iron toxicity screening

Lines K 408, K 455

S 304, S 203 were identified performing well in both field and hydroponic conditions $\llbracket$

Utilization in breeding program for identification of suitable parents under acidic soils

How to cite : Debnath, A., M. Rai and W. Tyagi: Identification of Swarna x O. nivara (RPBio4918) advanced backcross lines performing well under acidic soil conditions. J. Environ. Biol., 42, 240-246 (2021). 


\section{Introduction}

Rice (Oryza sativa L.) constitutes the staple food of 3.5 billion people worldwide and approximately $90 \%$ of the world's rice is grown in the Asian continent (El Namaky et al., 2017). In lowland-rice production, iron toxicity is well-recognized as the most widely distributed constraint. Iron toxicity is a complex nutrient disorder in acid soils due to the presence of excessive Fe uptake from flooded soils under reducing conditions. In flooded soil, $\mathrm{Fe}^{3+}$ in soil minerals is converted to $\mathrm{Fe}^{2+}$, and this $\mathrm{Fe}^{2+}$ is much more soluble in water, leading to an excess of Fe or iron toxicity in the soil solution (Kirk, 2004). Plants suffering with iron toxicity show symptoms like stunted growth, rusty leaf spots, stained leaf edges along with poorly developed root system.

Excessive uptake of $\mathrm{Fe}^{2+}$ by roots and its acropetal translocation via xylem flow into the leaves leads to expression of iron-toxicity symptoms. Accumulation of oxidized polyphenols in the leaf occurs due to excess amount of $\mathrm{Fe}^{2+}$ which can irreversibly damage cell structural components and lead to typical visual symptom "bronzing" of the rice leaves (Dobermann and Fairhurst, 2000). Majority of visual symptoms of Fe toxicity are commonly observed at tillering and heading stage, but, in severe Fe toxicity conditions, the effects can occur irrespective of any growth stage of rice crop and may lead to complete crop failure (Mahender et al., 2019). Mainly three major morphological and physiological mechanisms or strategies are used by rice plants to survive adverse iron-toxic soil conditions and large amount of iron in plants (Becker et al., 2005). Selection of tolerant or adapted rice genotypes can be done based on these strategies. In case of strategy I (exclusion/avoidance), plants exclude iron at root level and avoid of $\mathrm{Fe}^{2+}$ damage to the shoot tissue (root ion selectivity and rhizospheric oxidation).

Iron uptake in the roots of rice is by strategy II (inclusion/avoidance), but tissue damage may be avoided by either compartmentation where immobilization of active iron in old leaves or photosynthetically less active leaf sheath tissue or exclusion from the symplast. Strategy III (inclusion/tolerance) is probably due to enzymatic "detoxification" in the symplast, plants actually tolerate elevated levels of iron within leaf cells. Among the above mentioned three strategies iron exclusion by oxidation in the rhizosphere and detoxification of radicals in leaf cells are well established Fe-tolerance mechanisms of rice (Becker et al., 2005). Tissue tolerance for iron toxicity in rice is considered an important parameter for genetic studies (Gregorio et al., 2002). Genome-wide association study (GWAS) conducted with a population of 329 accessions representing all subgroups of rice to ferrous iron stress has led to better understanding for genetic and physiological mechanisms associated with iron toxicity tolerance (Matthus et al., 2015).

For crop improvement programme against iron toxicity tolerance, two types of selection are distinguished: direct selection which are based on yield and indirect selection using traits such as leaf bronzing score, leaf rolling, plant height, root and shoot biomass, tissue iron concentration, chlorophyll content or agronomic traits other than yield. In case of rice improvement programs against iron toxicity are mainly based on yield as direct selection and leaf bronzing score as a secondary trait for indirect selection (Sikirou et al., 2015). Screening genotypes which are tolerant to iron toxicity stress would be of immense importance in improving rice production in lowland acidic soil conditions. Field screening is essential to estimate the real phenotypic value of genotypes, but it is time and resource consuming.

Under field conditions, several deficiencies and toxicities often co-exist, and it becomes difficult to partition the effect of different nutrient stresses on genotypes. In the present study two sets of ABLs (BC2F8) derived from crosses between a rice mega-variety Swarna and two accessions of $O$. nivara collected from areas affected by problem soils of Bihar (IRGC81832) and Uttar Pradesh (IRGC81848), with Swarna being the recurrent parent (Swamy et al., 2012). Apart from their use as mapping resources, $A B L s$ in the background of popular varieties having chromosomal segments from wild donors that impart stress tolerance may directly be released as improved varieties. Therefore, these ABLs were evaluated under lowland acidic field conditions, and a subset was studied under iron toxic hydroponic condition to identify superior and contrasting ABLs, especially for molecular biological studies, as screening genotypes in artificial hydroponics conditions (Shimizu et al., 2005) allows us to dissect the response of a genotype to one particular nutrient toxicity or deficiency.

\section{Materials and Methods}

Plant material: A total of 194 ABLs (Advanced Breeding Lines) were transplanted randomly following augmented experimental design in lowland field of CPGS-AS, CAU(I), Umiam, Meghalaya, situated at $25^{\circ} 41$ latitude and $91^{\circ} 54$ longitude and $950 \mathrm{~m}$ above mean sea level.The $194 \mathrm{ABLs}$ are comprised of $123 \mathrm{~S}$ lines (Swarna x O. nivara (IRGC81848) and $71 \mathrm{~K}$ lines Swarna x 0. nivara (IRGC81832) at $\mathrm{BC}_{2} \mathrm{~F}_{9}$ generation. For screening of $\mathrm{ABLS}$ in the field, augmented design was followed where checks were replicated but treatments were used in single entry.

Field experiment: Screening of ABLs in the field, augmented design was followed and the experimental plot was divided into five blocks, each block containing three checks, i.e., Swarna, Shahsarang and Sahbhagi Dhan along with randomly allotted S and $\mathrm{K}$ lines. For each line data was recorded on ten plants for different parameters like number. of tillers per plant ( 30 days old and 60 days old) (TN30; TN60), days to $50 \%$ flowering (DTF), number. of panicles per plant (PPP), number. of grains per panicle, grain yield per plant (GYPP), plant height (PH), biological yield per plant (BY), 100 grain weight, percent spikelet fertility $(\mathrm{SF})$, panicle length $(\mathrm{PL})$, harvest index $(\mathrm{HI})$, bronzing score (BS). Bronzing score was based on a scale of 1-3 (1- less/damage; 2moderate damage and 3-severe damage) and was usually observed in older leaves (after 60 days of transplanting. Tillers per plant was measured after 30 and 60 days of transplanting. Traits like PPP, GYPP, BY, SF, PL, HI were recorded post-harvest.

Hydroponic experiment: Thirty seeds for each line were germinated on moist filter paper having deionised water and allowed to grow for 5 days. The five-day-old seedlings were transferred to plastic cups (with mesh top) containing Yoshida 
solution (Yoshida et al., 1976). Each cup contained 4 seedlings and a total of 4 cups (two for control and treatment each) were used per ABL. Control solution was $1 \mathrm{X}$ Yoshida solution at $\mathrm{pH} 5.0$ while the treatment solution maintained at $\mathrm{pH} 4.0$ had $200 \mathrm{mg} \mathrm{l}^{-1}$ iron sulphate $\left(\mathrm{FeSO}_{4}\right)$ intially and subsequently $300 \mathrm{mg} \mathrm{l}^{-1} \mathrm{FeSO}_{4}$. The solution was changed every 5 days and the seedlings were allowed to grow till 21 days. After 21 days of growth in control and treated solution, data like seedling height, bronzing score and root biomass, shoot biomass (after air drying) was recorded.

Statistical analyses: The data obtained from field experiment was subjected to online augmented design analysis available at Indian Agricultural Statistics Research Institute website (http://www.iasri.res.in/spadweb). The adjusted means were subjected to Analysis of Variance (ANOVA) using Statistical package for agricultural research (SPAR 2.0). The hydroponics data (mean, standard error and graphs) were analysed and plotted using excel.

\section{Results and Discussion}

In the present study, $194 \mathrm{ABLs}$ were screened under acidic field conditions with three varieties Swarna, Shahsarang and Sahbhagi Dhan as checks. Variance due to treatments (ABLs) was found to be significant for TN30 (range 2.20-11.00), PPP (range 2.0-15.00), FGPP, SF (range 0.37-87.79), GY (range 1.33-26.80) and BY (range 28.01-112.36) (Table 1). Coefficient of variation was found to be high for TN60, indicating that the trait was highly affected by microenvironmental conditions. This suggests that sufficient variability was present among the ABLs with respect to the above mentioned key traits. Highly significant $(F=165.62, P<0.001)$ values from one-way ANOVA was also confirmed in a set of Sri Lankan rice varieties and advanced breeding lines where difference in leaf bronzing score were studied at different growth stages(Siriwardana et al., 2019).

Superior and inferior ABLs were identified on the basis of performance with respect to four traits (TN30, PPP, SF and GY) that are mostly influenced by iron toxicity in acidic lowland soil. The performance of $K$ and $S$ lines with respect to these traits are indicated in Fig. 1, 2. Individual ABLs that performed better than the checks, especially the recurrent parent Swarna were identified for each of the four traits and are summarized in Table 2. Simultaneously, ABLs performing poorly with respect to the traits were also identified, which may be useful for subsequent mapping studies.

Table1: Analysis of Variance for Advanced backcross lines (ABLs)

\begin{tabular}{llllllllllll}
\hline & df & TN30 & TN60 & PH & DTF & PPP & df & FGPP & SF & BY & GY \\
\hline Treatments (Adjusted) & 1196 & $22.72^{* *}$ & 44.93 & 2244.24 & 666.63 & $55.59^{* *}$ & 554 & $4481.72^{* *}$ & $3395.73^{* *}$ & $2297.52^{* *}$ & $998.40^{* *}$ \\
Block (Adjusted) & 44 & $00.73^{* *}$ & 111.17 & 3358.87 & 1148.96 & $88.15^{* *}$ & 44 & $2211.23^{* *}$ & $1183.18^{* *}$ & $5544.58^{* *}$ & $88.99^{* *}$ \\
R $^{2}$ & & 00.997 & 00.98 & 00.99 & 00.94 & 11.00 & & 00.99 & 00.99 & 00.99 & 11.00 \\
Coefficient of variance & & 99.63 & 221.73 & 112.00 & 111.74 & 55.51 & & 113.00 & 111.26 & 66.91 & 77.92 \\
Root MSE & & 00.50 & 22.10 & 99.11 & 110.73 & 00.47 & 55.23 & 44.63 & 44.07 & 11.13 \\
General mean & & 55.21 & 99.66 & 775.97 & 991.35 & 88.56 & & 440.27 & 441.11 & 558.94 & 114.24 \\
\hline
\end{tabular}

Tn30- Tiller number at 30 days; TN60- Tiller number at 60 days; PH- Plant height; DTF- Days to 50\% flowering; PPP- Plants per pancilce; FGPP- Filled grains per panicle; SF- Spikelet fertility; BY- Biological yield; GY- Grain yield. df- Degrees of freedom; MSE- Mean square error. $\left({ }^{*}\right)=$ Significant at $5 \%$ level of significance; $\left.{ }^{* *}\right)=$ Significance $1 \%$

Table 2: Contrasting K and S series ABLs identified with respect to tillers per plant (TN30), number of panicles per plant (PPP), percent spikelet fertility (\% $\mathrm{SF}$ ) and grain yield per plant (GYPP)

\begin{tabular}{|c|c|c|c|c|c|c|c|c|}
\hline \multirow{2}{*}{$\begin{array}{l}\text { Traits } \\
\mathrm{K} \text { and } \mathrm{S} \text { series }\end{array}$} & \multicolumn{2}{|c|}{$\begin{array}{l}\text { Tillers per plant } \\
\text { (TN30) }\end{array}$} & \multicolumn{2}{|c|}{$\begin{array}{l}\text { Number of panicles } \\
\text { per plant (PPP) }\end{array}$} & \multicolumn{2}{|c|}{$\begin{array}{l}\text { Percent spikelet } \\
\text { fertility (SF) }\end{array}$} & \multicolumn{2}{|c|}{$\begin{array}{l}\text { Grain yield per } \\
\text { plant (GYPP) }\end{array}$} \\
\hline & $\mathrm{K}$ series & S series & $\mathrm{K}$ series & S series & $\mathrm{K}$ series & S series & K series & S series \\
\hline Mean value & 4.82 & 5.61 & 8.39 & 9.00 & 22.46 & 48.02 & 9.78 & 13.45 \\
\hline Variance & 2.26 & 3.23 & 10.20 & 4.45 & 349.93 & 300.70 & 28.65 & 28.09 \\
\hline Range & $2.2-11$ & $2.2-9.73$ & $0.39-14.89$ & $2.29-14.88$ & $0.37-68.72$ & $4.76-87.79$ & $1.33-23.14$ & $4.53-26.80$ \\
\hline Superior & K 417, & S 219, & K 410, & S 326 & K 450, & S 260. & K 410, & S 260, \\
\hline \multirow[t]{4}{*}{ performers (lines) } & K 416, & S 247, & K 456, & S 328, & K 448, & S 319 & K 437, & S 319 \\
\hline & K 419, & S 203, & K 413, & S 321, & K 447, & S 281, & K 447. & S 304, \\
\hline & $\mathrm{K} 418$ & S 262, & K 419, & S203, & K 455, & S 240, & K 413 & S 240, \\
\hline & K 415 & S 264 & K 416 & S 323 & K 410 & S 203 & & S 328 \\
\hline Inferior & K 429, & S 313, & K 450, & S 207, & K 422, & S 299, & K 450, & S 299, \\
\hline \multirow{4}{*}{ performers (Lines) } & K 436, & S 310, & K 449, & S 296, & K 440, & S 258, & K 440, & S 310 \\
\hline & K 440, & S 327, & K 435, & S 208, & K 417, & S 326, & K 422, & S 300 \\
\hline & K 442, & S 299, & K 414, & S 222, & K 409, & S 305, & K 448, & S 222, \\
\hline & K 422 & S 296 & K 436 & S 299 & K 441 & S 328 & K 408 & S 296 \\
\hline
\end{tabular}



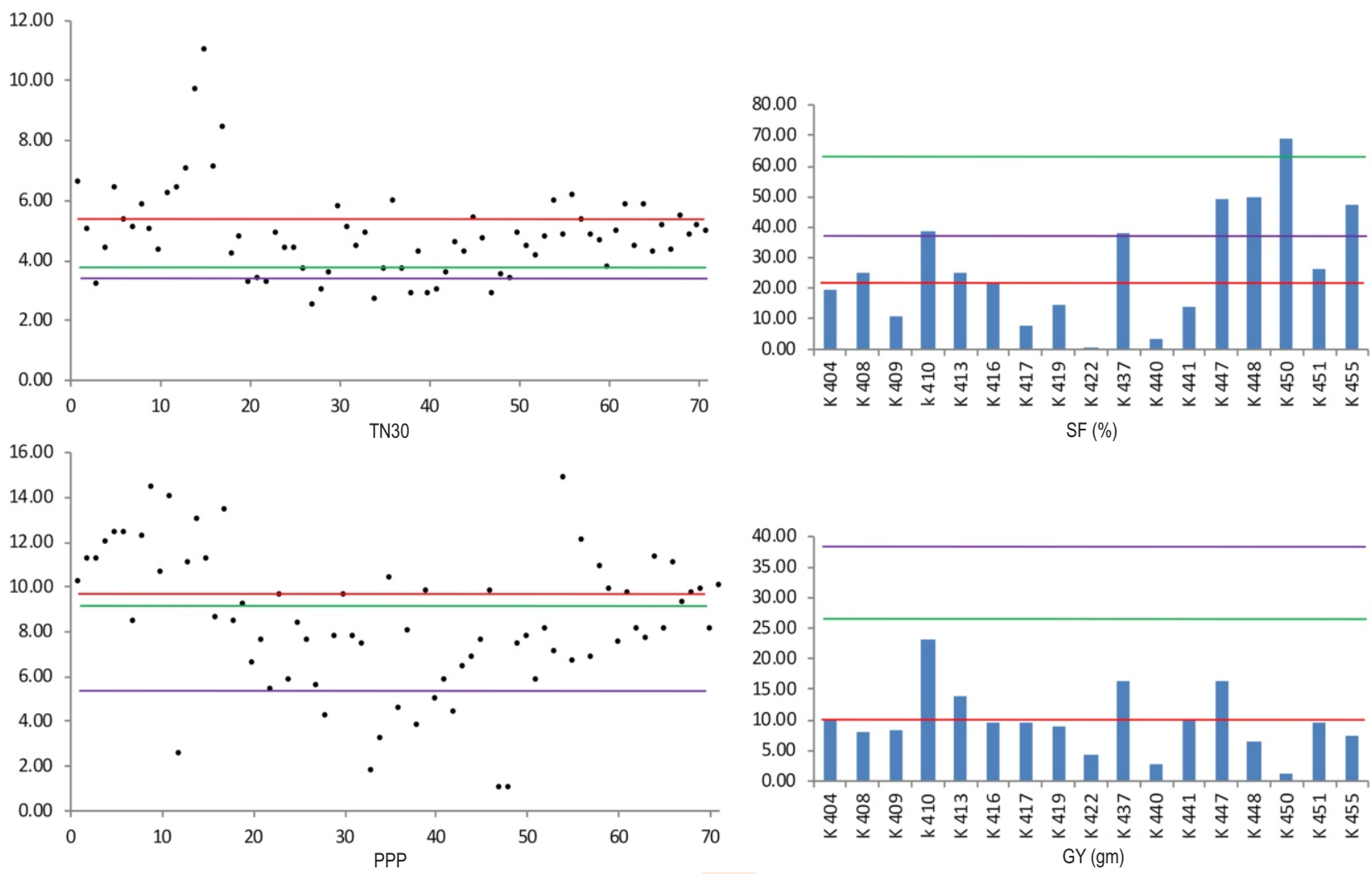

Fig. 1: Phenotypic variation observed under field conditions in $71 \mathrm{~K}$ series ABLs as compared with three check varieties with respect to tillers per plant (TN30), number of panicles per plant (PPP), percent spikelet fertility (SF) and grain yield per plant (GY). Post harvest data is only shown for a subset of lines representing the variation observed. Red, green and purple horizontal lines represent mean trait values of checks Swarna, Shahsarang and Sahbhagi dhan, respectively.

A majority of the $S$ series ABLs outperformed the checks for number of tillers at $30 \mathrm{DAT}$ and number of panicles per plant, indicating contribution of favourable alleles for the traits from donor O. nivara (IRGC81848). However, transgressive segregants in the case of $\mathrm{K}$ series ABLs were much lesser in proportion. Similarly, for grain yield per plant and spikelet fertility, the proportion of transgressive segregants observed were significantly higher in $S$ series ABLs. None of the ABLs were able to outperform the best check (Sahbhagi dhan) in terms of grain yield per plant. ABLs consistently performing well for all the traits were also identified. Differences in root morphology and biomass of $\mathrm{K}$ and $\mathrm{S}$ lines were also observed between superior and inferior ABLs as depicted in Fig 3. Similar studies in rice revealed that iron toxicity affects rice growth through difference in shoot and root development (Li et al., 2016; Wu et al., 2017). These differences due to Fe toxicity are more prominent in lowland rice field as more iron is available in reduced form. This condition affects the plant nutrition and ultimately decrease the crop yield (Morrissey et al., 2009; Kim et al., 2007). Gbeto-Dansou et al. (2017) also reported that plots with iron toxicity gives less yield as compared with plots not affected by toxicity. Depending on the severity of iron toxicity and also form of iron, plant growth is affected (Muller et al., 2015).
Although in some studies, intense iron toxicity symptoms are associated with lowest yield (Diedhiou et al., 2020) but most of the inferior lines identified in our study did not show iron toxicity symptoms. Previously a decrease in rice yield has been reported even in plots where plant did not show any symptoms of iron toxicity (Hua et al., 2001; Sikirou et al., 2015). Also, the leaf bronzing appreance appears to be non-significant in many cases but significant reduction in yield was observed (Sahrawat, 2004; Onaga et al., 2012). Soil heterogeneity or Genotype $x$ Environment interactions (GxE) might be the reason for creating such differences among lines. Even in the same field, variability in the distribution of iron leads to a large environmental errors and express different $G \times E$ interactions on rice yield which ultimately affects the breeding efficiency of genotype selection for iron toxicity tolerance (Cherif et al., 2006). Therefore, iron toxicity tolerance should be directed to multi locational trials as well as biophysical environmental analysis before establishing a variety (Piepho, 1996).

Fe toxicity tolerance screening for selected ABLs: Based on the field performance (Fig. 1, 2), a smaller set of contrasting ABLs (7 K lines- K 408, K 437, K 440, K 448, K 450, K 455 and 9 S linesS203, S 240, S296, S 300, S 304, S 307, S 310, S 312, S 323) 

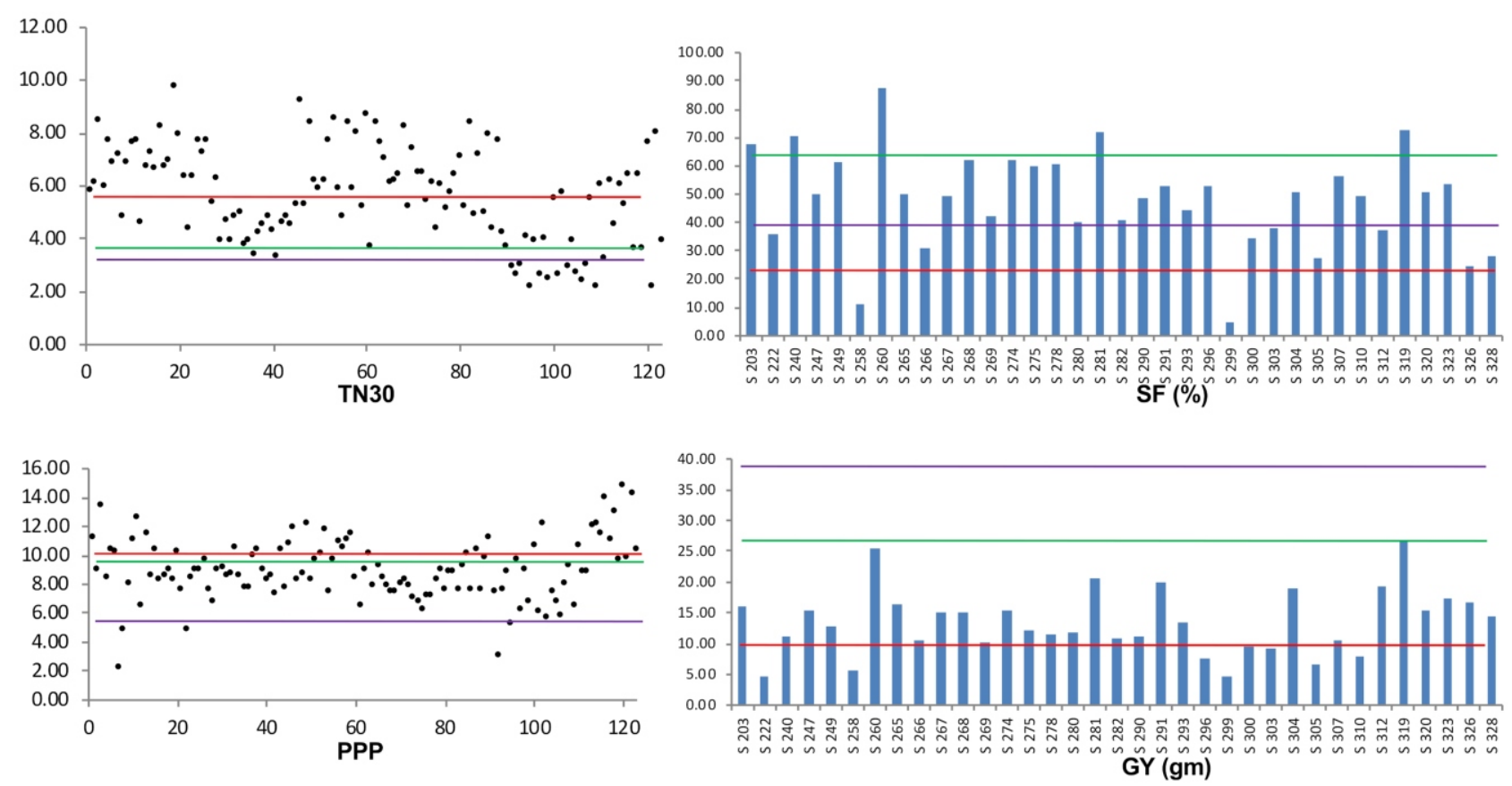

Fig. 2 : Phenotypic variation observed under field conditions in $123 \mathrm{~S}$ series ABLs as compared with three check varieties with respect to tillers per plant (TN30), number of panicles per plant (PPP), percent spikelet fertility (SF) and grain yield per plant (GY). Post harvest data is only shown for a subset of lines representing the variation observed. Red, green and purple horizontal lines represent mean trait values of checks Swarna, Shahsarang and Sahbhagi dhan, respectively.

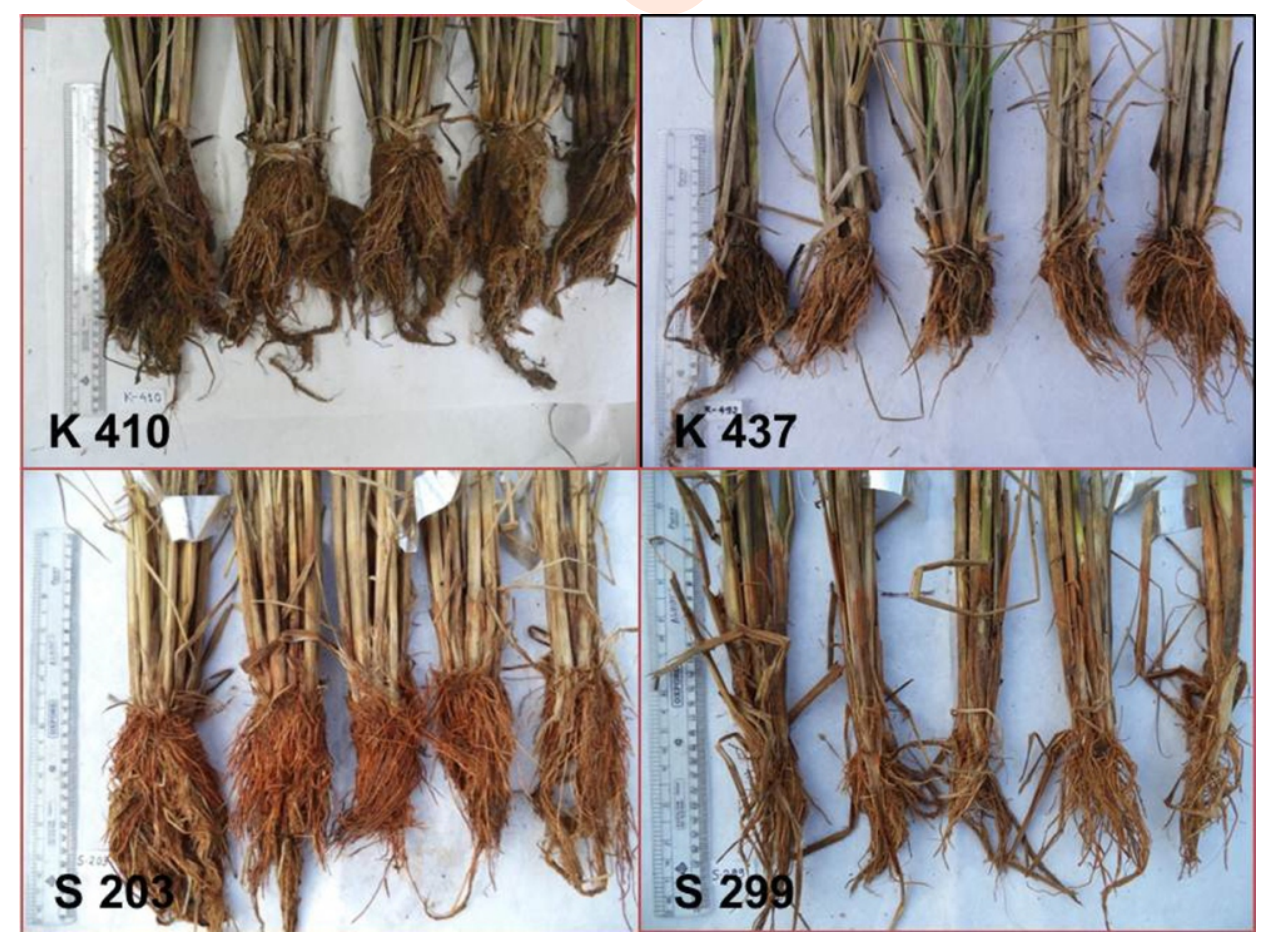

Fig. 3 : Representative picture showing differences in root morphology and biomass of superior and inferior $\mathrm{K}$ and $\mathrm{S}$ lines under acidic field conditions. Lines K 410, S-203 showed high root biomass and tiller number as compared to K 437, S-299 lines. 

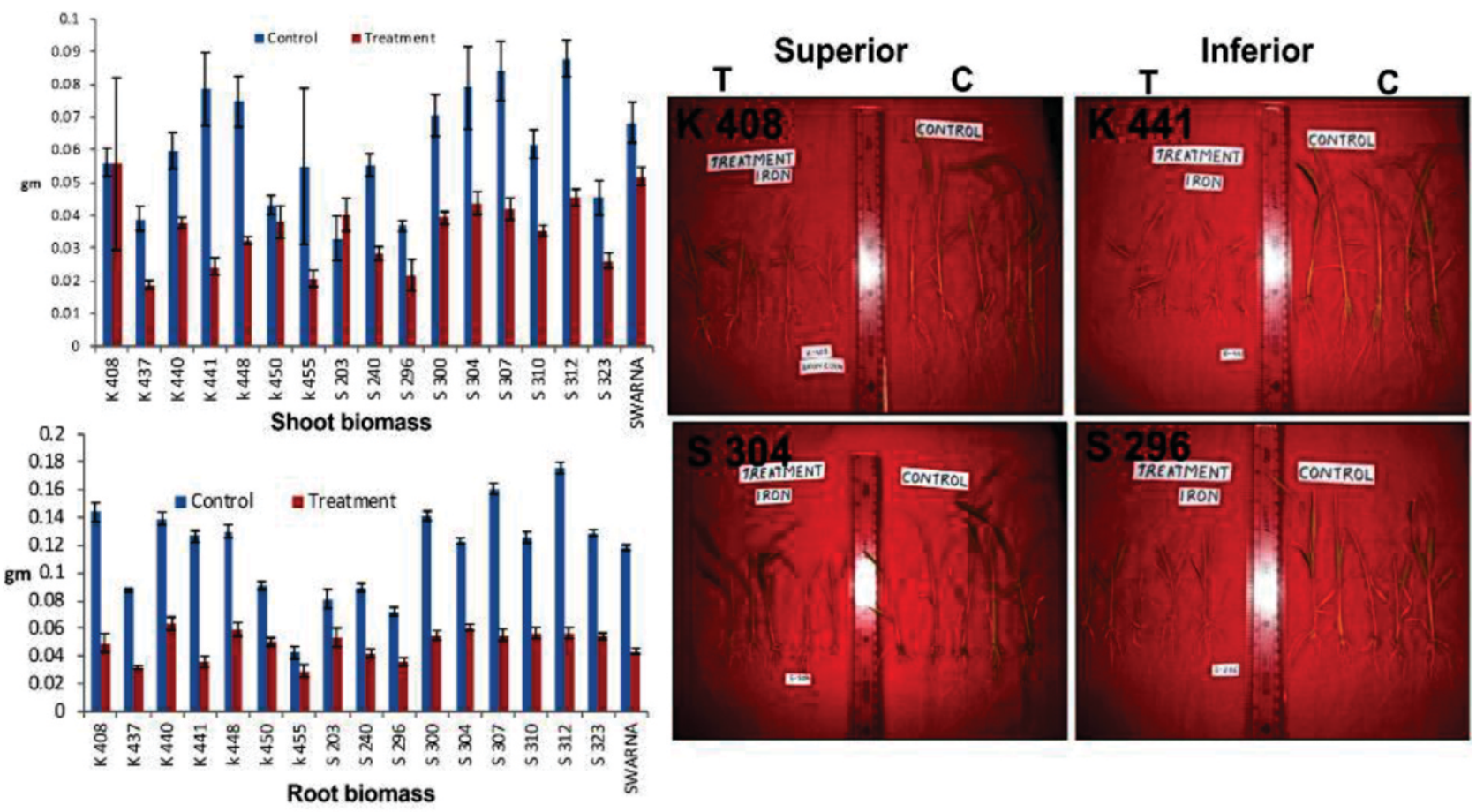

Fig. 4 : Variation in (a) shoot and root biomass among selected $\mathrm{K}$ and $\mathrm{S}$ lines and (b) representative picture of superior and inferior lines under control (C$2 \mathrm{mgl}^{-1} \mathrm{Fe}$ ) and treatment $\left(\mathrm{T}-200 \mathrm{mgl}^{-1} \mathrm{Fe}\right.$ ) hydroponic conditions.

along with their recurrent parent Swarna were evaluated under hydroponic condition in greenhouse in response to iron toxicity. Elec et al. (2013) carried out a similar study by establishing a nutrient-based screening method for rice. Data was recorded after 21 days after stress treatment. Traits like shoot biomass and root biomass were recorded. There was significant decrease in shoot biomass and root biomass in almost all the genotypes in (200 $\mathrm{mg} \mathrm{l}^{-1} \mathrm{Fe}$ ) as compared to control (2 $\mathrm{mg} \mathrm{l}^{-1} \mathrm{Fe}$ ) (Fig. 4a)). Symptoms like stunted growth, rusty leaf spots, stained leaf edges and a poorly developed root system and bronzing were observed in some lines (K 440, S240, S 312, and S 222). Superior lines (K 450, K 408, S 203, and S 304) and inferior lines (K 441, S 296) were selected based on shoot biomass and root biomass. Previously, using a set of $220 \mathrm{BC}_{3} \mathrm{DH}$ lines derived from the backcross O. Sativa (Caiapo)/ O. glaberrima (MG12)// O. sativa (Caiapo) screened in the presence or absence of iron (0 or 250 $\mathrm{mg} \mathrm{l}^{-1}$ ) revealed that that iron toxicity mechanism differs in cultivated rice and wild rice can be used as a source of resistance (Dufey et al., 2015).

In the present study, no significant correlation was found between the yield contributing traits under field conditions and the traits studied under hydroponic condition (data not shown). However, four superior ABLs (K 408, K 455, S 304, S 203) that performed consistently in acidic soil and hydropnoics screening were identified based field performance, root and shoot biomass under hydroponics and visual observations. Some of the poor performing lines identified were K 441, K 437, S 296 and S 300 (Fig. 4b)). The superior lines identified in this study can be used as potential donors for toxicity tolerance. As iron toxicity is a complex trait, crosses between superior and inferior lines can be used for mapping study as well. Previously, screening two different bi-parental mapping populations under iron pulse stresses Wu et al. (2014), followed by experiments with selected lines were able to shed light on genetic basis of shootbased Fe toxicity tolerance mechanisms (Wu et al., 2017), Similar strategy using wild rice species as donors has been used to generate important resources for mapping complex trait like yield (Reddy et al., 2005; Tian et al., 2006). In conclusion the phenotypic variations observed in this study suggests variable genome contribution from the donor parent (Oryza nivara) and this can be used effectively for QTL mapping. The four superior ABLs identified can be used as donors for mapping novel sources of iron toxicity tolerance in rice after further validation.

\section{Acknowledgments}

This work was supported by funds from Indian Council of Agricultural Research (ICAR) through National Agricultural Innovative Project (C30033/415101-036) and Central Agricultural University, Imphal CAU (I). The seeds for ABL (RPBio4918) were provided by Dr. N Sarla (ICAR National Professor, Indian Institute of Rice Research, Hyderabad).

\section{Add-on Information}

Authors' contribution: A. Debnath: Performed and designed the experiments, wrote draft and Final Page Proof; M. Rai: 
conceived the research plan, designed the experiments, analyzed the data and also reviewed and edited the paper, providing helpful comments and discussions; W. Tyagi: Conceived the research plan and designed the experiments, reviewed and edited the paper and helped in preparation of Final Page Proof.

Research content: The research content is original and has not been published elsewhere

\section{Ethical approval: NotApplicable}

Conflict of interest: The authors declare that there is no conflict of interest.

Data from other sources: NotApplicable

Consent to publish: All authors agree to publish the paper in Journal of Environmental Biology.

\section{References}

Becker, M. and F. Asch: Iron toxicity in rice - conditions and management concepts. J. Plant Nutr. Soil Sci.,168, 558-573 (2005).

Cherif, M., M. Fofana, A. Audebert and Z. Zouzou: Significant aspects of iron toxicity in West Africa. In: Iron toxicity in rice based system in West Africa (Eds.: A. Audebert, L.T., Narteh, P. Kiepe, D. Millar and B. Beks). WARDA, Cotonou., pp. 141-148 (2006).

Diedhiou, S., A.O.K. Goudiaby, Y.P. Sagna, Y. Diatta, M.D. Diallo and I. Ndoye: Effect of iron toxicity on rice growth in sulfato-ferruginous lowland of South Senegal. AJAF., 8, 9-14 (2020).

Dobermann, A. and T.H. Fairhurst. Rice: Nutrient disorders and nutrient management. The International Rice Research Institute, Manila, The Philippines, p. 191 (2000).

Dufey, I., X. Draye, S. Lutts, M. Lorieux, C. Martinez and P. Bertin: Novel QTLs in an interspecific backcross Oryza sativa $\mathrm{x}$ Oryzaglaberrima for resistance to iron toxicity in rice. Euphytica, 204, 609-625 (2015).

Elec V., C.A. Quimio, R. Mendoza, A.G.C. Sajise, S.E.J. Beebout, G.B. Gregorio and R.K. Singh: Maintaining elevated $\mathrm{Fe}^{2+}$ concentration in solution culture for the development of a rapid and repeatable screening technique for iron toxicity tolerance in rice (Oryza sativa L.). Plant Soil, 372, 253-264 (2013).

El-Namaky, R., M.M. Bare Coulibaly, M. Alhassan, K. Traore, F. Nwilene, I. Dieng, R. Ortiz and B. Manneh: Putting plant genetic diversity and variability at work for breeding, hybrid rice suitability in West Africa. Diversity, 9, 27 (2017).

Gbeto-Dansou, G.J., L.G.L. Amadji and H. Aholoukpe: Dynamics of ferrous iron $(\mathrm{FeO})$ in lowland soil as a function of water distribution according to the toposequence in southern Benin: Phenomenon of iron toxicity and rice production. J. Appl. Biosci., 110,10730-10746 (2017).

Gregorio, G.B., D. Senadhira, R.D. Mendoza, N.L. Manigbas, J.P. Roxas and C.Q. Guerta: Progress in breeding for salinity tolerance and associated abiotic stresses in rice. Field Crops Res., 76, 91-101 (2002).

Hua, L., Y. Xiaoe and L. Ancheng: Ameliorating effect of potassium on iron toxicity in hybrid rice. J. Plant Nutr., 24, 1849-1860 (2001).

Kim, S.A. and M. Guerinot: Lou: Mining iron: Iron uptake and transport in plants. FEBS Lett., 581, 2273-2280 (2007).

Kirk, G.J.D.: The biogeochemistry of submerged soils. John Wiley \&
Sons Ltd., Chichester (2004).

Li, G., H.J. Kronzucker and W. Shi: Root developmental adaptation to Fe toxicity: Mechanisms and management. Plant Signal. Behav., 11, e1117722 1-3 (2016).

Mahender, A., B.P.M. Swamy, A. Anandan and J. Ali: Tolerance of irondeficient and -toxic soil conditions in rice. Plants, 8, 31 (2019).

Matthus, E., L. Wu, Y .Ueda, S. Höller, M. Becker and M. Frei: Loci, genes, and mechanisms associated with tolerance to ferrous iron toxicity in rice (Oryza sativa L.) Theor. Appl Genet., 128, 2085-2098 (2015)

Morrissey, J. and M.L. Guerinot: Iron uptake and transport in plants: The good, the bad, and the ionome. Chem. Rev., 109, 4553-4567 (2009).

Muller, C., K.N. Kuki, D.T. Pinheiro, L.R. de Souza, A.I.S. Silva, M.E. Loureiro, M.A. Oliva and A.M. Almeida: Differential physiological responses in rice upon exposure to excess distinct iron forms. Plant Soil, 391,123-138 (2015).

Onaga, G., R. Edema and G. Asea: Tolerance of rice germplasm to iron toxicity stress and the relationship between tolerance, $\mathrm{Fe}^{2+}, \mathrm{P}$ and $\mathrm{K}$ content in the leaves and roots. Arch. Agron. Soil Sci., 59, 213-229 (2012).

Piepho, H.P.: Analysis of genotype-environment interaction and phenotypic stability. (Eds.: M.S. Kang and H.G. Gauch Jr.) Genotype-by-environment interaction, Boca Raton, FL: CRC Press, 151-174 (1996).

Reddy, M.P., N. Sarla, V.L.N. Reddy and E.A. Siddiq: Identification and mapping of yield and related QTLs from an Indian accession of $O$. rufipogon. BMC Genetics, 6, 33 (2005).

Sahrawat, K.: Iron toxicity in wetland rice and the role of other nutrients. J. Plant Nutr., 27, 1471-1504 (2004).

Shimizu, A., C.Q. Guerta, G.B. Gregorio, S. Kawasaki and H. Ikehashi: QTLs for nutritional contents of rice seedlings (Oryza sativa L.) in solution cultures and its implication to tolerance to iron-toxicity. Plant Soil, 275, 57-66 (2005).

Sikirou, M., K. Saito, E.G Achigan-Dako, K.N. Dramé, A. Ahanchédé and R. Venuprasad: Genetic limprovement of iron toxicity tolerance in rice-Progress, challenges and prospects in West Africa. Plant Prod. Sci., 18, 423-434 (2015).

Siriwardana, K.G.D.I., W.D.P. Weerasinghe, G.D.A. Priyantha, K.K.D. Chandrasekara, M.D.N. Rupasinghe, W.R.K.D.W.K.V. Wickramasinghe, I. Dissanayake and M.R. Wijesinghe: Screening of selected rice varieties and advanced breeding lines against iron toxicity under field conditions in the low country wet zone of Sri Lanka. J. Trop. Agric. Res., 30, 33-46 (2019).

Swamy, B.P.M., K. Kaladhar, N.S. Rani, G.S.V. Prasad, B.C. Viraktamath, G.A. Reddy and N. Sarla: QTL analysis for grain quality traits in $2 \mathrm{BC} 2 \mathrm{~F} 2$ populations derived from crosses between Oryza sativa cv Swarna and 2 accessions of $O$. nivara. J. Hered., 103, 442-452 (2012).

Tian, F.D.J., Q. Fu. Li, Z.F. Zhu, Y.C. Fu, X.K. Wang and C.Q. Sun: Construction of introgression lines carrying wild rice (Oryza rufipogon) segments in cultivated rice (Oryza sativa) background and characterization of introgressed segments associated with yield related traits. Theor. Appl. Genet., 112, 570-580 (2006).

Wu, L.B., Y. Ueda, S.K. Lai and M. Frei: Shoot tolerance mechanisms to iron toxicity in rice (Oryza sativa L.). Plant Cell Environ., 40, 570 -584 (2017).

Wu, L., M.Y. Shhadi, G. Gregorio, E. Matthus, M. Becker and M. Frei: Genetic and physiological analysis of tolerance to acute iron toxicity in rice. Rice, 7, 8 (2014).

Yoshida, S., D.A. Forno, J.H. Cock and K.A. Gomez: Laboratory manual for physiological studies of rice. Int. Rice Res. Insti. (IRRI), Los Baños (1976). 